\title{
Captação de águas pluviais: potencialidade em um residencial do sudeste do Pará
}

Este artigo tem por objetivo principal discutir sobre a potencialidade da implementação de microdrenagem para a captação das águas advindas da precipitação no município de Marabá, localizado na região sudeste do estado do Pará. O estudo se justifica pela importância de reaproveitar os recursos hídricos e minimizar a problemática das enchentes não só na região Amazônica, mas ao redor do mundo. Entende-se que um dos principais desafios da atualidade, especialmente em cidades de países em desenvolvimento, é lidar com estes tipos de problemas socioambientais, tendo em vista que os índices pluviométricos na região da cidade de Marabá apresentam elevadas concentrações em consideração a outras regiões no Brasil. Dessa forma, torna-se conveniente o aproveitamento desses volumes hídricos para posterior uso em atividades que não demandam a utilização de água com características de potabilidade, assim como recomendado pela Resolução CONAMA 357/05. Além disso, essa captação diminui o risco de alagamentos, o que oferece uma maior segurança para a população. Dessa forma, desenvolveu-se esta pesquisa exploratória em residências populares oferecidas pelo Governo Federal. A partir das análises e cálculos, concluiu-se que Marabá apresenta um grande potencial em termos de captação de águas pluviais, propondo, assim, a implantação de um sistema para captação de águas pluviais em residências do governo federal, seguindo as normas e padrões estabelecidos pela NBR 15527/07.

Palavras-chave: Captação de Águas Pluviais; Microdrenagem; Precipitação.

\section{Rainwater capture: potential in a residential in southeastern Pará}

The main objective of this paper is to discuss the potentiality of the implementation of microdrainage for the capture of rainwater in the municipality of Marabá, located in the southeastern region of the state of Pará. The study is justified by the importance of reusing water resources and minimizing flood problems not only in the Amazon region, but around the world. It is understood that one of the main challenges of today, especially in cities of developing countries, is to deal with these types of social and environmental problems, considering that rainfall rates in the Marabá city region present high concentrations in consideration to other regions in the world. Brazil. Thus, it is convenient to use these water volumes for later use in activities that do not require the use of water with potability characteristics, as recommended by Resolution CONAMA 357/05. In addition, this capture decreases the risk of flooding, which offers greater security for the population. Thus, this exploratory research was developed in popular residences offered by the Federal Government. From the analysis and calculations, it was concluded that Marabá has a great potential in terms of rainwater capture, thus proposing the implementation of a system for rainwater capture in federal government residences, following the norms and standards established NBR 15527/07.

Keywords: Rainwater abstraction; Microdrainage; Precipitation.

Topic: Desenvolvimento, Sustentabilidade e Meio Ambiente

Reviewed anonymously in the process of blind peer.
Received: 05/06/2019

Approved: 09/08/2019
Stephanie Jael Negrão de Freitas

Universidade Federal do Pará, Brasil

http://lattes.cnpq.br/1432769722634758

http://orcid.org/0000-0001-9917-5342

negro.stephanie@gmail.com

José de Souza Profilo Júnior (iD

Universidade do Estado do Pará, Brasil

http://lattes.cnpq.br/5072826848935777

http://orcid.org/0000-0002-9771-2340

juniorprofilo@gmail.com

Ana Carla Leite Carvalho Cabral

Universidade da Amazônia, Brasil

http://lattes.cnpq.br/6538382004505294

http://orcid.org/0000-0002-1735-1320

calincarvalho@gmail.com

\author{
Jucyanna Célia Lopes Lima \\ Universidade do Estado do Pará, Brasil \\ http://lattes.cnpq.br/7729517700652127 \\ http://orcid.org/0000-0001-5162-716X \\ jucyanna.lopes@gmail.com \\ Jeferson Botelho Rodrigues \\ Faculdade Pitágoras, Brasil \\ http://lattes.cnpq.br/9702846379230129 \\ http://orcid.org/0000-0001-6371-7912 \\ profilo.jr@gmail.com
}

Referencing this:

FREITAS, S. J. N.; PROFILO JÚNIOR, J. S.; CABRAL, A. C. L.; LIMA, J. C.; RODRIGUES, J. B.. Captação de águas pluviais: potencialidade em um residencial do sudeste do Pará. Nature and Conservation, v.12, n.2, p.31-37, 2019. DOI: http://doi.org/10.6008/CBPC23182881.2019.002.0004

DOI: 10.6008/CBPC2318-2881.2019.002.0004 


\section{INTRODUÇÃO}

Segundo Rezende et al. (2013), um dos principais desafios da atualidade, especialmente em cidades de países em desenvolvimento, é lidar com a problemática das cheias, enchentes e alagamentos. À medida que a população cresce, as manchas urbanas aumentam desordenadamente, e novas áreas são ocupadas a cada dia. Ocorre, assim, aumento da geração de esgotos domésticos, aumento da atividade industrial e da poluição por ela geradas, bem como há um aumento dos resíduos sólidos urbanos e industriais, uma vez que o ciclo hidrológico sofre alterações significativas que acabam influenciando também a qualidade das águas (FINOTTI et al., 2009).

Finotti et al. (2009) ainda ressalta que o desenvolvimento dos centros urbanos, geralmente, significa aumento da impermeabilização do solo pela pavimentação das ruas, lotes, construção de moradias e outras obras de infraestrutura. Essa alta impermeabilização tem impactos significativos no regime de vazões das pequenas bacias localizadas na área urbana, havendo, consequentemente, alteração no padrão de escoamento superficial. A prática atual de projetos de drenagem pluvial é o de transportar para a jusante todo o excesso de água gerado pela impermeabilização. Desta forma, à medida que o escoamento se desloca para a jusante é acrescido de novos aumentos de volume devido a urbanização, resultando em acréscimos significativos na vazão máxima (TUCCl et al., 1998).

Tucci (1993) ainda propõe que, para as consequências da urbanização, não sejam transportadas para a jusante, é necessário o seu controle na fonte, ou seja, na microdrenagem. Compõem o sistema de microdrenagem as vias urbanas, as sarjetas, o meio-fio, as 'bocas de lobo', os tubos e conexões. Entretanto, existem formas mais alternativas que visam a redução dos impactos da urbanização sobre o comportamento hidrológico das bacias, bem como sistemas de captação para aproveitamento de águas pluviais instalados em domicílios. O aproveitamento de água da chuva possui uma lógica simples e de fácil compreensão: consiste de um modelo de manejo da água precipitada, em que se empregam superfícies impermeáveis tais como superfície de captação (VELOSO et al., 2014).

Para Annecchini (2005), o sistema de aproveitamento de água da chuva é considerado um sistema descentralizado de suprimento de água, cujo objetivo é de conservar os recursos hídricos, reduzindo o consumo de água potável. Diante disso, a água captada e armazenada significa uma expressiva economia no gasto de água potável. Uma vez que ela pode ser utilizada para fins não potáveis, bem como lavagem das calçadas, de automóveis, irrigações de canteiros e jardins, para limpeza em geral, dentre outros. Outrossim, a retenção de águas pluviais, principalmente nos centros urbanos, onde possuem boa parte do solo impermeabilizado por ruas, calçadas e edificações, contribui para diminuição de alagamentos, enchentes e cheias.

Ao considerar os altos índices de intensidade pluviométrica da cidade de Marabá (PA), como serão apresentados neste estudo, o presente artigo propõe o aproveitamento de água da chuva para fins não potáveis e ressalta a potencialidade de implementação de sistemas de captação em casas populares no 
município, uma vez que se complementa ao objetivo de conservar os recursos hídricos e reduzir o consumo de água potável para outros fins.

\section{MATERIAIS E MÉTODOS}

\section{Área de Estudo}

A área de estudo está localizada na BR-222, Km 11,5, no Núcleo Morada Nova cerca de 13km a norte da Nova Marabá (figura 1). Chamado de 'O Jardim do Éden', esse conjunto habitacional faz parte do Programa Minha Casa Minha Vida, do Governo Federal, totalizando 968 (novecentos e sessenta e oito) residências, com um número de 3800 (três mil e oitocentos) moradores.

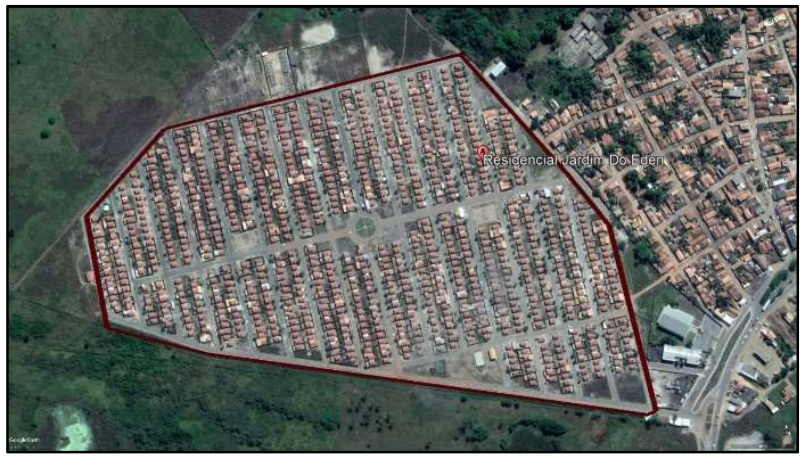

Figura 1: Localização da área de estudo.

\section{Tipo de Pesquisa}

A metodologia da pesquisa neste caso, caracteriza-se como exploratória. A construção deste estudo desenvolveu-se em um cenário de núcleo residencial com características arquitetônicas similares. No caso deste estudo, fora comparada a quantidade (em metros cúbicos) dos usos "não potáveis", das águas a fim de substituí-las pelas águas da chuva, discutindo a viabilidade do sistema e a possibilidade de implantação de microdrenagem nessas residências.

\section{Coleta de Dados}

Para a obtenção das variáveis para realizar os cálculos de possibilidades, tem-se o 'volume residencial' $\left(\mathrm{m}^{3}\right)$, consumido por uma residência com cinco moradores. Os dados foram obtidos com informações da Companhia de Saneamento do Estado Pará. A outra variável foi o 'volume água da chuva' $\left(m^{3}\right)$ em estudo à captação para uso domiciliar.

À captação em estudo, pode-se desenvolver pela simples coleta por meio de calhas no telhado da área estudada onde a água pode ser direcionada para um reservatório a fim de ser reaproveitada. A primeira água que cai acaba 'lavando' o telhado e não há potencial de reaproveitamento, mas o restante pode servir para diversas atividades domésticas. O estudo em questão resume-se na utilização do uso para fins não potáveis da água captada. Para o cálculo da variável 'volume de água pluvial' obteve-se dados empíricos, que foram as médias mensais de água precipitada do ano 2004 até 2013, coletados nos dados da Agência Nacional 
de Águas (ANA 2018), no período de chuva, que compreende os meses de janeiro até dezembro sucessivamente.

\section{Análise de dados}

Após obtenção dos dados das duas variáveis, foi comparado o uso da água residencial ao uso da água captada, em volume $\left(\mathrm{m}^{3}\right)$, para atingir a dimensão do quanto pode-se economizar e quais os setores que se pode fazer o uso de água pluvial, para a verificação da viabilidade do sistema. Para o trato dos dados, faz-se o uso do Microsoft Office Excel, ferramenta necessária para tabulação e análise dos dados matemáticos para poder correlacionar as variáveis, analisando a viabilidade da implantação do sistema de captação. Os dados da variável 'volume residencial' foram obtidos segundo a classificação da categoria e subcategoria de economia em função da utilização do imóvel da Companhia de Saneamento do Pará - COSANPA, nos meses de chuva do ano de 2004 a 2013.

\section{RESULTADOS}

Os dados apresentados na tabela 1 referem-se aos meses de chuva, que compreendem de janeiro até dezembro, no período de 2004 até 2013. Fora considerado uma perda por evaporação de $10 \%$ da água a ser armazenada. A tabela 2 apresenta o cálculo da obtenção da água da chuva armazenada para o uso permitido $\left(\mathrm{m}^{3}\right)$. Para obtenção do volume de água da chuva, dimensionou-se a área do reservatório pela área do telhado da casa $\left(65 \mathrm{~m}^{2}\right)$. A partir disso, propõe-se a tabela 2 .

Tabela 1: Precipitação dos meses chuvosos entre 2004-2013 em Marabá.

\begin{tabular}{|c|c|c|c|c|c|c|c|c|c|c|c|}
\hline \multicolumn{10}{|c|}{ Precipitação $(\mathrm{mm})$} \\
\hline Ano & 2004 & 2005 & 2006 & 2007 & 2008 & 2009 & 2010 & 2011 & 2012 & 2013 & Média Adotada \\
\hline Janeiro & 482,1 & 81,3 & 160,4 & 203,8 & 515,9 & 258,7 & 337,4 & 351,7 & 293,5 & 239,9 & 292,47 \\
\hline Fevereiro & 444,5 & 292,5 & 319,5 & 509,5 & 385,8 & 383,4 & 267 & - & 386,2 & 108 & 309,64 \\
\hline Março & 247,3 & 424,2 & 347,3 & 267,5 & 646,3 & 310,8 & 283,7 & 448,8 & 395,5 & 195,6 & 356,7 \\
\hline Abril & 250,4 & 243,7 & 286,8 & 236,3 & 379,1 & 478,8 & 287,4 & 244 & - & 354,2 & 276,07 \\
\hline Maio & 30,5 & 120,1 & 232,64 & 28 & 287,2 & 459 & 66,3 & 50,3 & 116,5 & 194,3 & 158,484 \\
\hline Junho & 9,5 & 2,3 & 4,3 & 17,5 & 43,3 & 17,8 & 5,8 & 54 & 36,6 & 30 & 22,11 \\
\hline Julho & 17,9 & 3,4 & 1,2 & 6,3 & 0 & 25 & 13,2 & 23 & 42,3 & 22,7 & 15,5 \\
\hline Agosto & 45,4 & 0 & 0 & 0 & 32,2 & 17 & 19,8 & 5,5 & 0 & 9,5 & 12,94 \\
\hline Setembro & 11,5 & 39,5 & 17,8 & 17,2 & 54,5 & 45,5 & 50,5 & 28,5 & - & 65,5 & 33,05 \\
\hline Outubro & 166,5 & 60,4 & 18,9 & 140 & 63,7 & 182 & 192,5 & 127 & - & 67,6 & 101,86 \\
\hline Novembro & 175 & 65,9 & 307,2 & 110,9 & - & 29 & 155,4 & 121,2 & 113,7 & 53,6 & 113,19 \\
\hline Dezembro & 136,3 & 339,1 & 79,78 & 174,5 & 238,4 & 316 & 154 & 250,5 & 140 & 99,7 & 192,828 \\
\hline
\end{tabular}

Fonte: ANA (2018)

Tabela 2: Cálculo da obtenção da água da chuva armazenada para o uso permitido $\left(\mathrm{m}^{3}\right)$.

\begin{tabular}{|c|c|c|c|}
\hline Meses & Média Adotada $(\mathrm{m})$ & Área do Telhado $\left(\mathrm{m}^{2}\right)$ & Volume de Águas Pluviais $\left(\mathrm{m}^{3}\right)-10 \%$ \\
\hline Janeiro & 0,292 & 65 & 17,082 \\
\hline Fevereiro & 0,31 & 65 & 18,135 \\
\hline Março & 0,357 & 65 & 20,8845 \\
\hline Abril & 0,276 & 65 & 16,146 \\
\hline Maio & 0,158 & 65 & 9,243 \\
\hline Junho & 0,022 & 65 & 1,287 \\
\hline Julho & 0,015 & 65 & 0,8775 \\
\hline
\end{tabular}




\begin{tabular}{|c|c|c|c|}
\hline Agosto & 0,013 & 65 & 0,7605 \\
\hline Setembro & 0,033 & 65 & 1,9305 \\
\hline Outubro & 0,102 & 65 & 5,967 \\
\hline Novembro & 0,113 & 65 & 6,6105 \\
\hline Dezembro & 0,193 & 65 & 11,2905 \\
\hline
\end{tabular}

A água é captada por meio de calhas no telhado e levada até o reservatório. Multiplicando-se a média adotada $(\mathrm{m})$ pela área do reservatório $\left(\mathrm{m}^{2}\right)$ temos o volume de água para o uso permitido (já considerada a perda por evaporação). Na tabela 3, apresenta-se a porcentagem de aproveitamento do volume captado em relação ao volume residencial consumido. Nota-se que o percentual de aproveitamento superou em $50 \%$ o volume residencial consumido (uso potável e não potável) pela casa em estudo. Analisando $60 \%$ do volume residencial pelo volume captado, temos os valores supridos nos meses de janeiro a dezembro, como apresentados na tabela 4.

Tabela 3: Porcentagem de aproveitamento do volume captado pelo residencial consumido.

\begin{tabular}{|c|c|c|c|}
\hline Meses & $\begin{array}{c}\text { Volume Água Pluvial } \\
\left(\mathrm{m}^{3}\right)\end{array}$ & $\begin{array}{c}\text { Volume Residencial } \\
\left(\mathrm{m}^{3}\right)\end{array}$ & $\begin{array}{c}\text { Porcentual de } \\
\text { aproveitamento (\%) }\end{array}$ \\
\hline Janeiro & 17,082 & 20 & 85,41 \\
\hline Fevereiro & 18,135 & 20 & 90,675 \\
\hline Março & 20,8845 & 20 & 104,4225 \\
\hline Abril & 16,146 & 20 & 80,73 \\
\hline Maio & 9,243 & 20 & 6,435 \\
\hline Junho & 1,287 & 20 & 4,3875 \\
\hline Julho & 0,8775 & 20 & 3,8025 \\
\hline Agosto & 0,7605 & 20 & 9,6525 \\
\hline Setembro & 1,9305 & 20 & 29,835 \\
\hline Outubro & 5,967 & 20 & 33,0525 \\
\hline Novembro & 6,6105 & 20 & 56,4525 \\
\hline Dezembro & 11,2905 & 20 & \\
\hline
\end{tabular}

Fonte: ANA (2018).

Tabela 4: Porcentagem do volume residencial (60\%, utilizado para usos não potáveis) pelo volume captado das chuvas.

\begin{tabular}{|c|c|c|c|}
\hline Meses & Volume Residencial $\left(\mathrm{m}^{3}\right)$ & $\begin{array}{c}60 \% \text { Volume } \\
\text { Residencial }\left(\mathrm{m}^{3}\right)-\text { Uso } \\
\text { não potável }\end{array}$ & $\begin{array}{c}\text { Volume Água Pluvial } \\
\left(\mathrm{m}^{3}\right)\end{array}$ \\
\hline Janeiro & 20 & 12 & 17,082 \\
\hline Fevereiro & 20 & 12 & 18,135 \\
\hline Março & 20 & 12 & 20,8845 \\
\hline Abril & 20 & 12 & 16,146 \\
\hline Maio & 20 & 12 & 9,243 \\
\hline Junho & 20 & 12 & 1,287 \\
\hline Julho & 20 & 12 & 0,8775 \\
\hline Agosto & 20 & 12 & 0,7605 \\
\hline Setembro & 20 & 12 & 1,9305 \\
\hline Outubro & 20 & 12 & 5,967 \\
\hline Novembro & 20 & 12 & 6,6105 \\
\hline Dezembro & 20 & 12 & 11,2905 \\
\hline
\end{tabular}

Fonte: ANA (2018).

\section{DISCUSSÃO}

A figura 2 apresenta o comparativo entre o porcentual do volume usado em uma residência (60\% para usos não potáveis) pelo volume captado das chuvas (que poderia ser usado para o mesmo fim). Nota- 
se que, na maioria dos meses, é possível aproveitar a água da chuva para os fins não potáveis pela água tratada servida pela concessionária.

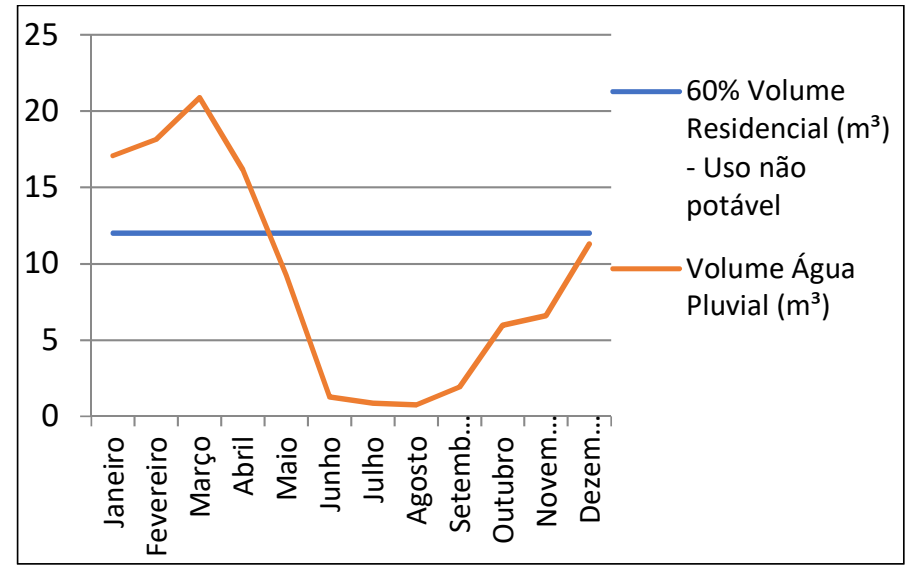

Figura 2: Comparativo entre as variáveis: volume água da chuva e uso permitido.

O sistema de captação de água pluvial mostrou-se efetivo para suprir a demanda de água para uso não potável. Porém, a região de estudo mostrou que, para uma residência com cinco pontos de utilização, o índice pluviométrico somente conseguiu tornar o sistema auxiliar de distribuição de água $100 \%$ eficiente em um período ininterrupto de quatro meses, entre janeiro e abril. Após esse período, o sistema não consegue satisfazer essa necessidade sozinho sendo sugerido a utilização mista com o sistema de abastecimento disponibilizado pela COSANPA.

Os sistemas de aproveitamento de água da chuva surgem como uma das principais alternativas para melhorar a gestão do uso do recurso hídrico, implicando diretamente em benefícios socioambientais. Segundo et al. (2015) realizou um estudo de captação de águas pluviais na cidade de João Pessoa (PB), e ao final, os resultados obtidos mostraram que a implantação de tal sistema apresentou um potencial elevado de captação de água da chuva com impactos ambientais favoráveis ao consumo de água, redução de valores pagos por tarifas e dessa forma proporcionando uma melhor viabilidade econômica e ambiental.

Zhang et al. (2019), em seu estudo projetando cenários futuros (2020-2050), notou que o desempenho de economia de água é afetado positivamente pelos aumentos nas chuvas futuras em quatro cidades chinesas e que os sistemas de captação devem ser resilientes as mudanças climáticas. Flores et al. (2012) demonstrou que, na cidade de Belém (PA), o atendimento com água da chuva poderia ocorrer no mínimo para $18 \%$ da população (cerca de 200 mil pessoas) e no máximo para cerca de $37 \%$ da população (cerca de 420 mil pessoas), sendo que a água da chuva tem potencial significativo de sanar o déficit de abastecimento da cidade de Belém.

\section{CONSIDERAÇÕES FINAIS}

A partir das informações dispostas neste estudo, pode-se considerar que a utilização de água da chuva, além de trazer o benefício da conservação da água e reduzir a dependência excessiva das fontes superficiais de abastecimento, reduz o escoamento superficial e da chance a restauração do ciclo hidrológico nas áreas urbanas, sendo este extremamente necessário para garantir o desenvolvimento sustentável. Além 
da viabilidade econômica, a implementação de microdrenagem promove a sustentabilidade, uma vez que contribui para conscientização do uso da água, no caso, os sistemas de captação de águas pluviais.

Nesse tipo de técnica, é imprescindível que as residências sejam dotadas de calhas e condutores para o direcionamento da água da chuva do telhado ao reservatório. Portanto, é importante que uma atenção especial seja dada ao dimensionamento desses componentes que podem reduzir significativamente a eficiência de coleta, comprometendo o funcionamento de todo o sistema de água da chuva, podendo-se utilizar como referência para o dimensionamento desses componentes a NBR 15527/2007 - Instalações Prediais de 2 Águas Pluviais da ABNT.

\section{REFERÊNCIAS}

ABNT. Associação Brasileira de Normas Técnicas. NBR 15527/07: Instalações Prediais de Águas Pluviais. Rio de Janeiro: ABNT, 2007.

ANA. Agência Nacional das Águas. Hidroweb: Sistemas de informações hidrológicas. Brasília: ANA, 2018.

ANA. Agência Nacional de Águas. A Evolução da Gestão dos Recursos Hídricos no Brasil. Brasília: ANA, 2002.

ANNECCHINI, K. P. V.. Aproveitamento da água da chuva para fins não potáveis na cidade de Vitoria (ES). Dissertação (Mestrado) - Universidade Federal do Espirito Santo, Vitória, 2005.

FINOTTI, A. R.; FINKLER, R.; SILVA, M. D.; CEMIN, G.. Monitoramento de recursos hídricos em áreas urbanas. Caxias do Sul: EDUCS, 2009.

FLORES, R. A.; MENDES, R. L. R.; OLIVEIRA, D. R. C.; COSTA, T. C. D.; VELOSO, N. S. L.. Potencial de captação de água de chuva para abastecimento: o caso da cidade de Belém (PA, Brasil). Estudos Tecnológicos em Engenharia, v.8, n.2, p.6980, 2012.

OLIVEIRA, L. H.. Projeto Tecnologias para Construção Habitacional mais Sustentável: Levantamento do estado da arte: Água. São Paulo: USP, 2007.
REZENDE, O. M.; MIGUEZ, M. G.; VERÓL, A. P.. Manejo de águas urbanas e sua relação com o Desenvolvimento Urbano em Bases Sustentáveis Integradas: Estudo de caso dos Rios Pilar-Calombé, em Duque de Caxias/RJ. Revista Brasileira de Recursos Hídricos, v.18, n.2, 2013.

SEGUNDO, S. T. L. R.; LIMA FILHO, M. R. F.. Estudo do potencial de captação e Aproveitamento da água da chuva em Prédios Públicos: Um projeto piloto para prédios do Semiárido da Paraíba. In: WORKSHOP INTERNACIONAL SOBRE ÁGUA NO SEMIÁRIDO BRASILEIRO, 2. Anais. Campina Grande: UFCG, 2015.

TUCCI, C. E. M.. Hidrologia: ciência e aplicação. Porto Alegre: EDUSP, 1993.

TUCCI, C. E. M.; CRUZ, A. S.; SILVEIRA, A. L. L.. Controle do escoamento com detenção em lotes urbanos. Revista Brasileira de Recursos Hídricos, v.3, n.4, 1998.

VELOSO, N. S.; MENDES, R. L. R.. Aproveitamento da água da chuva na Amazônia: Experiências nas Ilhas de Belém-PA. Revista Brasileira de Recursos Hídricos, v.19, n.1, 2014.

ZHANG, S.; ZHANG, J.; YUE, T.; JING, X.. Impacts of climate change on urban rainwater harvesting systems. Science of the total environment, v.665, p.262-274, 2019.

A CBPC - Companhia Brasileira de Produção Científica (CNPJ: 11.221.422/0001-03) detém os direitos materiais desta publicação. Os direitos referem-se à publicação do trabalho em qualquer parte do mundo, incluindo os direitos às renovações, expansões e disseminações da contribuição, bem como outros direitos subsidiários. Todos os trabalhos publicados eletronicamente poderão posteriormente ser publicados em coletâneas impressas sob coordenação da Sustenere Publishing, da Companhia Brasileira de Produção Científica e seus parceiros autorizados. Os (as) autores (as) preservam os direitos autorais, mas não têm permissão para a publicação da contribuição em outro meio, impresso ou digital, em português ou em tradução. 